\title{
Diagnóstico ambiental de NASCENTES do Rio Gaviãozinho No MUNicípio de Planalto-BA
}

\author{
Marcela Aparecida Frois de Andrade ${ }^{1 *}$, Flávia Mariani Barros ${ }^{2}$, Nicole Lopes Bento ${ }^{3}$
}

1 Discente do curso de pós-graduação em Meio Ambiente e Desenvolvimento pela Universidade Estadual do Sudoeste da Babia, Estrada Itapetinga/Itambé, s/n, CEP: 457000-00, Itapetinga- BA, Brasil.

2 Docente na Universidade Estadual do Sudoeste da Babia Estrada Itapetinga/Itambé, s/n, CEP: 457000-00, Itapetinga-BA, Brasil.

3 Discente do curso de Engenharia Ambiental pela Universidade Estadual do Sudoeste da Bahia, Estrada Itapetinga/Itambé, s/n, CEP: 457000-00, Itapetinga - BA, Brasil.

*Autorpara correspondência: marcelafrois@hotmail.com

Recebido em 17 de maio de 2017. Aceito em 02 de dezembro de 2018. Publicado em 31 de dezembro de 2018.

Resumo - O objetivo do presente trabalho foi caracterizar nascentes do rio Gaviãozinho do município de Planalto-BA quanto às áreas de preservação permanente, cobertura do solo e qualidade da água. Para tanto, foi realiza a classificação de uso do solo, ao redor de cada nascentes estudada, com o auxílio do Software ArcGis 10.0, bem como análise das variáveis de qualidade da água: $\mathrm{pH}$, Oxigênio Dissolvido (OD), Demanda Bioquímica de Oxigênio (DBO), Condutividade Elétrica (CE) e Turbidez. Foram identificadas 08 nascentes principais e apenas $25 \%$ destas estavam preservadas, em conformidade com a legislação vigente e $75 \%$ estavam degradadas, não atendendo à legislação, sem raio mínimo de cinquenta metros de vegetação natural. Nas nascentes preservadas, a qualidade da água apresentou menores variações nos parâmetros avaliados quando comparadas à maioria das nascentes degradadas, sendo as variáveis turbidez (8,49 a 104,0 UNT), CE (30,08 a 1139,23 $\left.\mu \mathrm{S} \mathrm{cm}{ }^{-1}\right)$ e DBO (2,99 a 9,39 $\left.\mathrm{mg} \mathrm{L}^{-1}\right)$ as que mais evidenciaram essas diferenças. De acordo com a Resolução CONAMA 357, em relação às variáveis turbidez e pH todas as nascentes estariam na condição de qualidade classe 1, bem como para variável OD, com exceção das nascentes N2 e N8 que estariam na condição de qualidade classe 3.

Palavras-chave: Cobertura vegetal; Conservação de nascentes; Parâmetros de Qualidade de água.

Diagnóstico ambiental de nacientes del río Gaviãozinho en el municipio de Planalto-BA

REsumen - El objetivo del presente trabajo fue caracterizar nacientes del río Gaviãozinho del municipio de Planalto-BA en relación a las áreas de preservación permanente, cobertura del suelo y calidad del agua. Para ello, se realizó la clasificación de uso del suelo, alrededor de cada naciente estudiada, con el auxilio del Software ArcGis 10.0, así como análisis de las variables de calidad del agua: pH, Oxígeno Disuelto (OD), Demanda Biológica de Oxígeno (DBO), Conductividad Eléctrica (EC) y Turbidez. Se identificaron ocho nacientes principales y solo se conservaron el $25 \%$ de las nacientes evaluadas, de acuerdo con la legislación vigente y el $75 \%$ fueron degradadas, no cumpliendo con la legislación, sin el radio mínimo de cincuenta metros de vegetación natural. En las nacientes preservadas, la calidad del agua presentó menores variaciones en los parámetros evaluados en comparación con la mayoría de las degradadas, siendo las variables de turbidez (8,49 a 104,0 UNT), CE (30,08 a $\left.1139,23 \mu \mathrm{S} \mathrm{cm}^{-1}\right)$ e DBO (2,99 a 9,39 $\left.\mathrm{mg} \mathrm{L}^{-1}\right)$ las que más evidenciaron estas diferencias. De acuerdo con la Resolución 357 del CONAMA, en relación con las variables de turbidez y pH, todas las nacientes estarían en la condición de calidad clase 1, así como para la variable OD, con la excepción de las nacientes N2 y N8 que estarían en la condición de calidad de clase 3.

Palabras clave: Cobertura vegetal; Conservación de nacientes; Parámetros de Calidad del agua. 


\section{Environmental diagnosis of the Gaviãozinho River springs in the municipality of Planalto-BA}

Aвstract - The objective of the present study was to characterize springs of Gaviãozinho River in the municipality of Planalto-BA regarding permanent preservation, soil cover and water quality. In order to do so, it was carried out the classification of soil use, around each spring studied, with the technical support of ArcGis 10.0 Software, as well as analysis of water quality variables: pH, Dissolved Oxygen (DO), Biochemical Oxygen Demand (BOD), Electrical Conductivity (EC) and Turbidity. Eight major springs were identified and only 25\% of the springs evaluated were preserved, in accordance with current legislation and $75 \%$ were degraded, not complying with the legislation of a minimum radius of fifty meters of natural vegetation. In the preserved springs, the water quality presented smaller variations in the evaluated parameters when compared to most of the degraded springs, being the turbidity (8.49 to 104.0 UNT), EC (30.08 to $\left.1139.23 \mu \mathrm{S} \mathrm{cm}{ }^{-1}\right)$ and BOD (2.99 to $9.39 \mathrm{mg} \mathrm{L}^{-1}$ ) variables the ones that most evidenced these differences. According to CONAMA Resolution 357, in relation to turbidity and $\mathrm{pH}$ variables all springs would be in the class 1 quality condition, as well as for the DO variable, with the exception of springs N2 and N8 that would be in class 3 quality condition.

Keywords: Vegetation COVER; WATER CONSERVATION; Water QUALITY PARAMETERS.

\section{INTRODUÇÃO}

A degradação dos recursos naturais tem sido foco de inúmeras discussões, causando preocupação em diversos segmentos da sociedade, uma vez que as diminuições dos recursos podem colocar em risco a humanidade. A degradação ambiental é um processo que pode ser causado pela ação antrópica ou pela própria natureza, podendo ocasionar a diminuição atual e futura da capacidade produtiva do ecossistema, limitando o desenvolvimento da fauna e flora (Hüller 2011).

A vegetação exerce diretamente influência na qualidade das águas, seja em torno da bacia hidrográfica ou nas áreas que permeiam o corpo d'água. A mata ciliar, formação vegetal localizada nas margens dos corpos d'água é considerada pelo Código Florestal como "Área de Preservação Permanente (APP)", possuindo diversas funções ambientais, devendo respeitar uma extensão específica de acordo com a largura do ambiente hídrico (Brasil 2012).

As Áreas de Preservação Permanente possuem grande importância na manutenção da qualidade da água dos mananciais (Bueno et al. 2005; Donádio et al. 2005; Primavesi et al. 2002; Lima e Zakia 2001). Entretanto no Brasil, o debate em torno da importância das APPs gera muitas polêmicas sobre a área a ser protegida. Grande parte das APP's não está preservada, o que pode causar uma série de problemas em bacias hidrográficas, tais como: assoreamento do canal fluvial, aumento da erosão, diminuição da permeabilidade do solo e a consequentemente perda de nutrientes do mesmo dentre outros.

Segundo Gomes et al. (2005) o sistema de nascentes é constituído pela vegetação, solo, rochas e relevo das áreas adjacentes e a montante das nascentes, sendo de extrema importância, a preservação do mesmo. As nascentes quaisquer que sejam sua localização, de acordo com o novo Código Florestal Lei n¹2.651/12 deverão ter APP no raio mínimo de 50 (cinquenta) metros (Brasil 2012).

As ações antrópicas podem contribuir de maneira relevante para o avanço da degradação da vegetação ciliar, comprometendo principalmente, a estrutura das nascentes, que por estarem sem cobertura estão sujeitas ao desaparecimento (Silva Junior 2015), sendo que, no município de Planalto são observadas ações antrópicas no entorno das nascentes, o que pode comprometer o fluxo e qualidade da água.

Diante da degradação ambiental ocorrida por meio da ação antrópica, a sociedade está em busca de mudanças que visam a diminuir os impactos causados ao ambiente, sendo essas fundamentais para a sobrevivência humana e futuras gerações. Sendo assim, a recuperação de áreas afetadas torna-se cada vez mais necessária frente ao ritmo crescente da degradação ambiental que ocorre em diversos ecossistemas (Martins 2001). 
Desta forma, o objetivo deste trabalho foi fazer um levantamento e caracterização de nascentes do rio Gaviãozinho, no município de Planalto-BA, quanto às áreas de preservação permanente, cobertura do solo e qualidade da água.

\section{MATERIAL E MÉtodos}

\section{Caracterização da área}

A área avaliada está localizada no meio rural do município de Planalto, na Região Sudoeste do Estado da Bahia (Figura 1). O município de Planalto está localizado na mesorregião Sul Baiano e na microrregião de Vitória da Conquista, localizado a $465 \mathrm{~km}$ da capital do Estado, possui área de 826,062km², altitude de 943 metros com clima Semiárido e Subúmido a Seco (Sei 2017). A vegetação do município é caracterizada por Floresta Estacional Decidual e Floresta Ombrófila Densa e tradicionalmente, predominam as atividades de bovinocultura extensiva e a cafeicultura (Sei 2017).

Figura 1. Localização geográfica da sub-bacia hidrográfica do rio Gaviãozinho e da bacia hidrográfica do rio Catolé Grande.
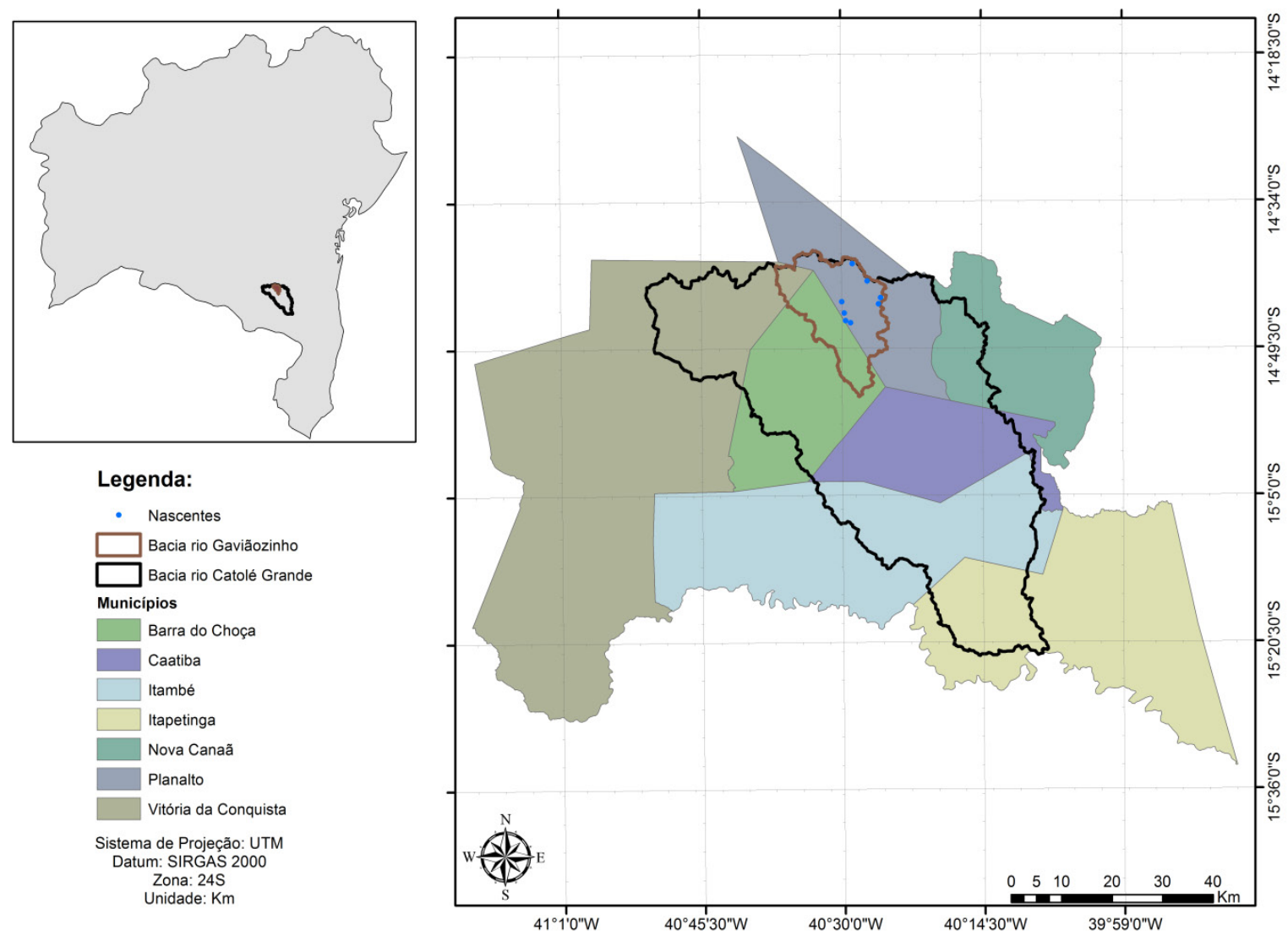

O estudo foi realizado com as nascentes do rio Gaviãozinho as quais pertencem à bacia hidrográfica do rio Catolé Grande (Figura 2). A Sub-bacia Hidrográfica do rio Catolé Grande é composta pelos municípios de Vitória da Conquista, Itambé, Barra do Choça, Caatiba, Itapetinga, Nova Canaã e Planalto (Figura 1). A nascente do rio Catolé Grande está situada no planalto de Vitória da Conquista, próximo à cidade de Barra do Choça, sendo seu desague na calha do rio Pardo, no sentido Nordeste-Sudeste, com seção de controle a jusante à cidade de Itapetinga 
(Barros 2011). O município de Planalto não é banhado pelo rio Catolé Grande e sim por afluentes importantes desse rio.

Nos dias que antecederam a coleta (11 a 18 de outubro de 2016), de acordo com os dados obtidos no Instituto nacional de meteorologia (estação 83344), foram observadas lâminas de precipitação de 0,7; 6,6 e 1,7 mm respectivamente nos dias 11, 12 e 14/10/2018.

Figura 2. Nascentes estudadas do rio Gaviãozinho no município de Planalto-BA.

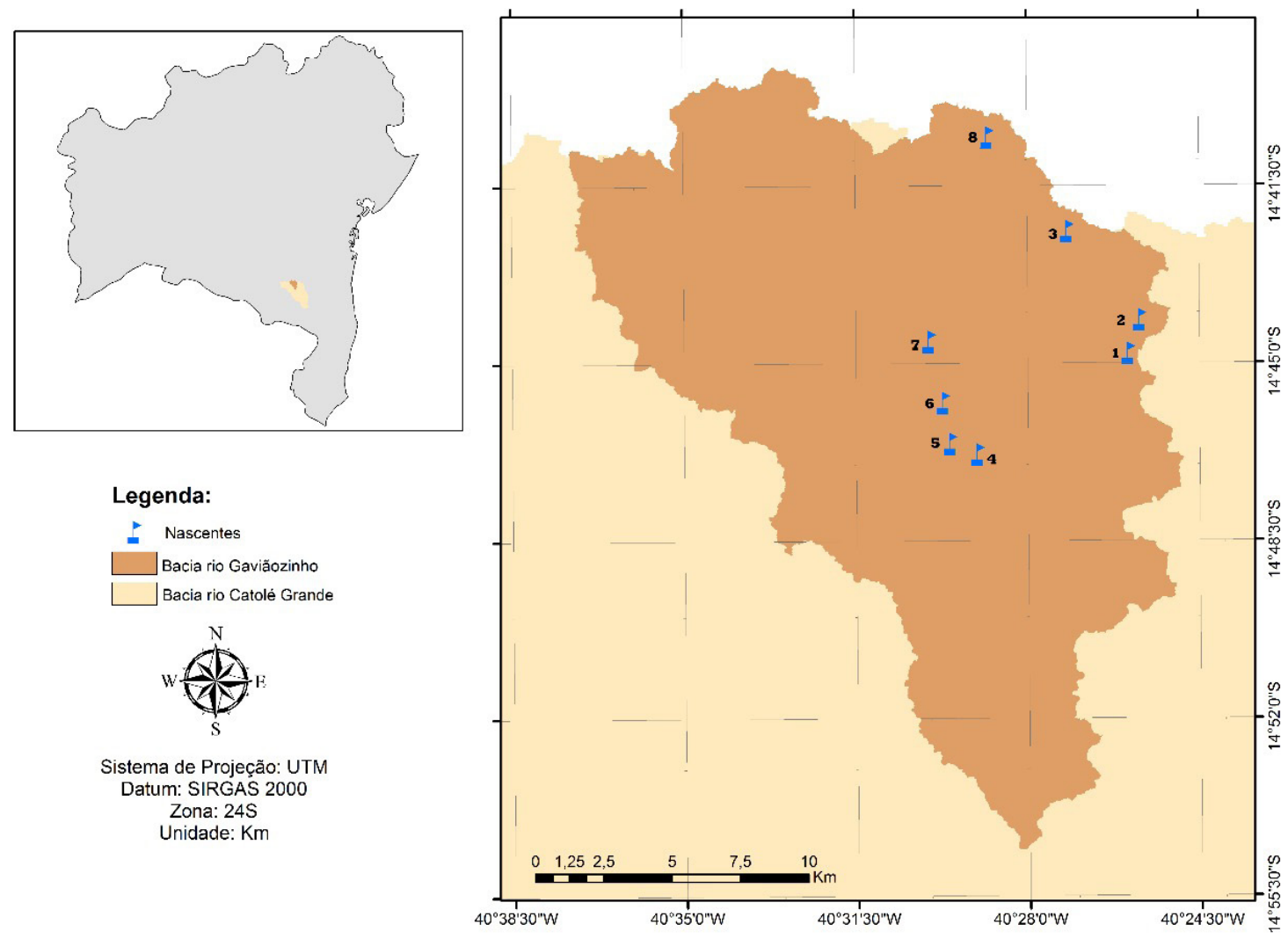

Dados coletados

Nesse estudo foi considerada nascente cada início dos tributários do rio Gaviãozinho dentro dos limites no município de Planalto, sendo identificadas 08 nascentes principais (Figura 02). As coordenadas geográficas das respectivas nascentes foram obtidas utilizando-se um receptor GPS Garmin Etrex $20 \AA$, as quais foram utilizadas para localizar as nascentes e mensurar a cobertura do solo no seu entorno, com o auxílio do Software ArcGis 10.0.

A determinação do uso e ocupação do solo foi feita em ambiente de Sistema de Informações Geográficas (SIG) sendo o mapeamento realizado por meio de classificação visual de imagens de satélite RapidEye, datada de 2012 a 2014, em sistema de projeção UTM, Datum SIRGAS 2000 zona 24 S em software ArcGis 10.0. A classificação foi realizada para toda a bacia do rio Catolé Grande e seus afluentes, e posteriormente realizado o recorte com raio de 50 metros para cada nascente de estudo, permitindo a identificação das classes de uso do solo.

Para caracterizar o grau de conservação da cobertura vegetal das nascentes foi adotada metodologia utilizada por Pinto et al. (2004). As nascentes ainda foram classificadas quanto à presença de vegetação no seu entorno com base na legislação vigente (Brasil 2012).

A coleta da água foi realizada no dia 18 de outubro de 2016, de forma manual, com três repetições, utilizando frascos de polipropileno na profundidade de 15 a $30 \mathrm{~cm}$, para evitar a introdução de contaminantes superficiais conforme NBR 9897 (ABNT 1987). Os frascos foram acondicionados em caixas de isopor e levados diretamente 
para o Laboratório de Dispersão de Poluentes (LADIP) da Universidade Estadual do Sudoeste da Bahia para a realização das análises.

As variáveis determinadas foram: $\mathrm{pH}$, Oxigênio Dissolvido (OD), Demanda Bioquímica de Oxigênio (DBO), Condutividade Elétrica (CE) e Turbidez. $\mathrm{O}$ pH da água foi obtido pelo método eletrométrico, com peagâmetro marca Digimed, modelo DM - 22. A condutividade elétrica foi obtida por meio de condutivímetro marca Digimed, modelo DM - 32. A turbidez foi determinada em laboratório, pelo método nefelométrico, utilizando-se turbidímetro, marca Digimed, modelo DM-TU - 0 a 1000 UNT. As concentrações de OD na água foram determinadas de acordo com o método de Winkler (1988) modificado. A determinação da demanda bioquímica de oxigênio (DBO) foi realizada pelo método descrito na NBR 12614/1992 (Brasil 1992).

Segundo a resolução CONAMA 357/2005 (Brasil, 2005), para corpos de água doce que ainda não tiveram seu enquadramento efetivado, essas serão consideradas classe 2 , desta maneira, as variáveis analisadas no presente estudo e que constam na resolução, foram comparadas com os padrões de qualidade para água doce classe 2 , visto que as nascentes avaliadas ainda não foram enquadradas.

A partir dos resultados obtidos e quando o teste $\mathrm{F}$ foi significativo, utilizou-se o teste de Tukey a $5 \%$ de probabilidade para verificar diferença entre as médias das variáveis de qualidade de água entre as nascentes avaliadas.

\section{Resultados E Discussão}

\section{Grau de preservação das nascentes}

O uso da água das nascentes estudadas é basicamente para consumo animal e as principais atividades desenvolvidas nestas áreas são a cafeicultura e a bovinocultura de corte. Observa-se que em muitas áreas houve substituição das matas ciliares por pastagem e o uso da água das nascentes estudadas é basicamente para consumo animal.

Na Tabela 1 está apresentada a localização e estado de preservação das nascentes, conforme metodologia descrita por Pinto et al. (2004).

O processo histórico de ocupação do território do município de Planalto revestiu-se de um caráter exploratório dos recursos naturais com desmatamentos para a produção agropecuária. Entre as inúmeras consequências, a ocupação indiscriminada atingiu duramente as áreas mais apropriadas para a manutenção de florestas, principalmente as de alta declividade, topos de morros e as matas ciliares. 
Tabela 1. Localização, tipo de cobertura do solo no entorno e análise do grau de preservação das nascentes diagnosticadas do rio Gaviãozinho na cidade de Planalto-BA, de acordo com metodologia proposta por Pinto et al. (2004).

\begin{tabular}{|c|c|c|c|c|c|}
\hline Nascentes & $\begin{array}{c}\text { Área de } \\
\text { preservação } \\
(\text { Lei no } \\
12651 / 12)\end{array}$ & Coordenadas & Região & $\begin{array}{c}\text { Principal cobertura do } \\
\text { solo }\end{array}$ & $\begin{array}{c}\text { Nível de } \\
\text { preservação } \\
\text { (Preservada, } \\
\text { perturbada } \\
\text { degradada) }\end{array}$ \\
\hline N1 & Não ${ }^{1}$ & $\begin{array}{l}\text { S -14 } 44^{\circ} 44^{\prime} 48.90^{\prime \prime} \\
\text { W }-40^{\circ} 25^{\prime} 56.52^{\prime \prime}\end{array}$ & Parafuso & Café+pastagem & Degradada $^{3}$ \\
\hline $\mathbf{N} 2$ & Não ${ }^{1}$ & $\begin{array}{l}S-14^{\circ} 44^{\prime} 10.65^{\prime \prime} \\
\text { W }-40^{\circ} 25^{\prime} 42.67^{\prime \prime}\end{array}$ & Caratinga & Café & Degradada $^{3}$ \\
\hline N3 & Não ${ }^{1}$ & $\begin{array}{l}\text { S }-14^{\circ} 42^{\prime} 24.66^{\prime \prime} \\
\text { W }-40^{\circ} 27^{\prime} 11.98^{\prime \prime}\end{array}$ & Massaranduba & Pastagem & Degradada $^{3}$ \\
\hline N4 & $\operatorname{Sim}^{2}$ & $\begin{array}{l}S-14^{\circ} 46^{\prime} 47.22^{\prime \prime} \\
\text { W - } 40^{\circ} 29^{\prime} 1.35^{\prime \prime}\end{array}$ & Lucaia & Floresta Ombrófila & Preservada ${ }^{4}$ \\
\hline N5 & $\operatorname{Sim}^{2}$ & $\begin{array}{l}\text { S - } 14^{\circ} 45^{\prime} 45.93^{\prime \prime} \\
\text { W }-40^{\circ} 29^{\prime} 43.35^{\prime \prime}\end{array}$ & Lucaia & Floresta Ombrófila & Preservada ${ }^{4}$ \\
\hline N6 & Não ${ }^{1}$ & $\begin{array}{l}\text { S - } 14^{\circ} 46^{\prime} 35.50^{\prime \prime} \\
\text { W }-40^{\circ} 29^{\prime} 34.09^{\prime \prime}\end{array}$ & Lucaia & Pastagem & Degradada $^{3}$ \\
\hline N7 & Não ${ }^{1}$ & 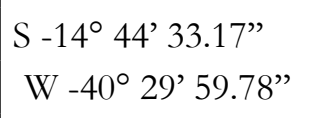 & Lucaia & Pastagem & Degradada $^{3}$ \\
\hline N8 & Não ${ }^{1}$ & $\begin{array}{l}\text { S }-14^{\circ} 40^{\prime} 34.23^{\prime \prime} \\
\text { W }-40^{\circ} 28^{\prime} 48.27^{\prime \prime}\end{array}$ & $\begin{array}{l}\text { Lagoa dos } \\
\text { coelhos }\end{array}$ & Pastagem & Degradada $^{3}$ \\
\hline
\end{tabular}

${ }^{1}$ Em não conformidade com a legislação, Lei n. ${ }^{\circ}$ 12.651/2012 (Brasil 2012), quando não há presença de preservação permanente com pelo menos 50 metros de vegetação natural ao seu redor.

${ }^{2}$ Em conformidade com a legislação, Lei n. ${ }^{\circ}$ 12.651/2012 (Brasil 2012), quando há presença de área de preservação permanente com pelo menos 50 metros de vegetação natural ao seu redor.

${ }^{3}$ Degradada: nascente que se encontra com elevado grau de perturbação, solo compactado, vegetação escassa e com erosão ou voçoroca.

${ }^{4}$ Preservada: nascente que apresenta pelo menos 50 metros de vegetação natural ao seu redor, previstos na Lei n. ${ }^{\circ} 12.651 / 2012$ (Brasil 2012), e sem sinais de perturbação ou degradação.

\section{Cobertura do solo no entorno das nascentes}

Na Figura 3 estão apresentados os esquemas das oito nascentes e classificação de uso do solo no seu entorno, considerando um raio de 50 metros conforme determina a Lei n. ${ }^{\circ}$ 12.651/2012 (Brasil 2012) para Área de Preservação Permanente. 
Figura 3. Cobertura do solo no raio de $50 \mathrm{~m}$ ao redor das oito nascentes estudadas do rio Gaviãozinho no município de Planalto-BA.

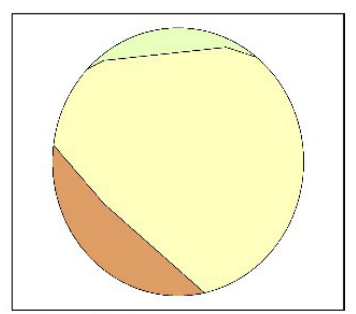

Nascente 1

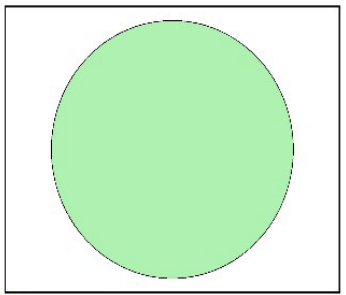

Nascente 4

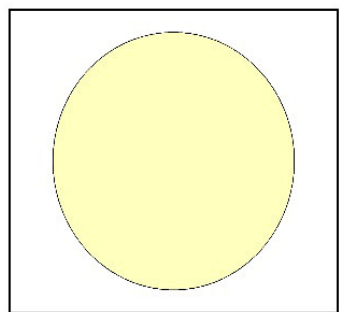

Nascente 7

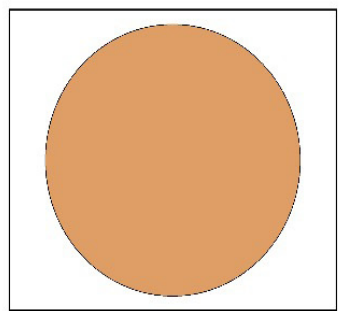

Nascente 2

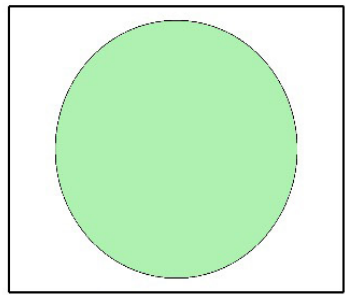

Nascente 5

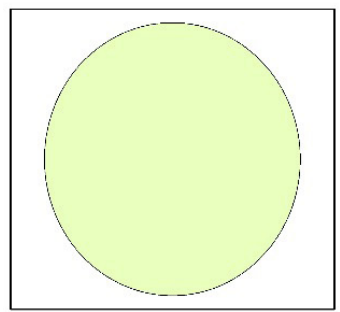

Nascente 8

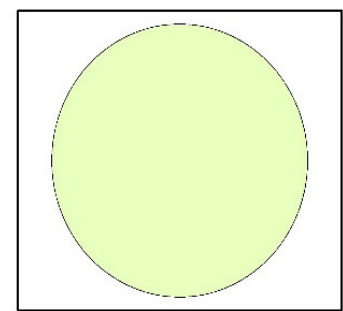

Nascente 3

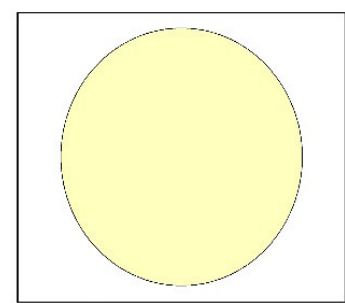

Nascente 6

Legenda:

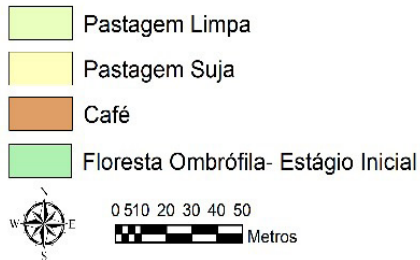

Tabela 2.Porcentagem de cobertura do solo das nascentes do rio Gaviãozinho na cidade de Planalto-BA no raio de 50 metros.

\begin{tabular}{|c|c|c|c|c|}
\hline Nascentes & Pastagem suja & Pastagem limpa & Café & $\begin{array}{c}\text { Floresta Ombrófila } \\
\text {-Estágio inicial }\end{array}$ \\
\hline N1 & $82 \%$ & $7 \%$ & $11 \%$ & - \\
N2 & - & - & $100 \%$ & - \\
N3 & - & $100 \%$ & - & - \\
N4 & - & - & - & $100 \%$ \\
N5 & - & - & - & $100 \%$ \\
N6 & $100 \%$ & - & - & - \\
N7 & $100 \%$ & - & - & - \\
N8 & - & $100 \%$ & - & - \\
\hline
\end{tabular}

A Nascente 1 (Figura 3) está localizada na região do Parafuso, e não está em conformidade com a legislação vigente (Brasil 2012), pois não possui o raio mínimo de 50 metros de vegetação natural recomendados e foi classificada como degradada, segundo metodologia de Pinto et al. (2004). O solo no entorno da nascente está ocupado por $11 \%$ de pasto limpo e $82 \%$ de pasto sujo e ainda possui uma área de $11 \%$ margeada com a cultura do café (Tabela 2). O olho d'água da nascente está cercado com arame farpado, mas existe uma bomba instalada para captação da água para o abastecimento da sede da propriedade (Figura 4). O canal de condução da água também não está protegido por vegetação natural e o gado tem livre acesso à área que seria de APP da nascente. 
Figura 4. Nascentes do rio Gaviãozinho no município de Planalto - BA.

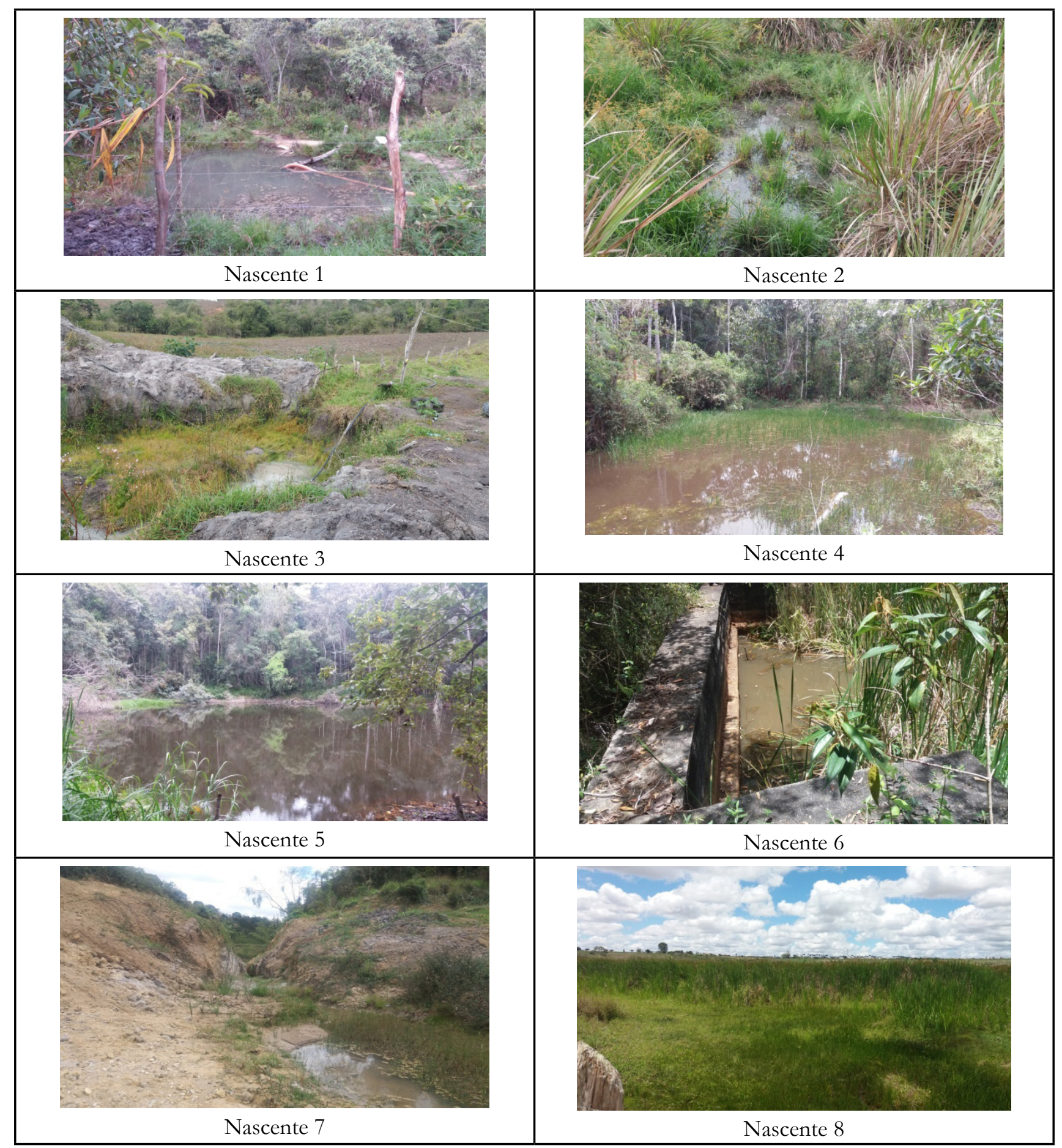

A Nascente 2 (Figura 3) está localizada na região da Caratinga está margeada em 100\% com lavoura de café (Tabela 2) e possui total acesso do gado para dessedentação. Não existe nenhum tipo de cercamento no entorno da nascente para sua preservação (Figura 4). Foram encontrados resíduos sólidos nas suas proximidades, dentre eles embalagens de larvicidas que são utilizados no gado. Essa nascente foi classificada como degradada, segundo metodologia de Pinto et al. (2004), não estando em conformidade com a legislação vigente que determina o raio mínimo de $50 \mathrm{~m}$ de vegetação nativa no entorno da nascente (Brasil 2012).

A Nascente 3 (Figura 3) localizada na região da Massaranduba encontra-se degradada, conforme metodologia de Pinto et al. (2004) e margeada em 100\% com pastagem limpa (Tabela 2). É perceptível a degradação dessa nascente, onde foram utilizadas máquinas para escavar o solo bem no seu afloramento, com o provável e equivocado intuito de realizar uma "limpeza" da área para maior minação da água (Figura 4). A Nascente 3 não está em conformidade com a legislação vigente (Brasil 2012), pois não possui vegetação natural no seu entorno. 
A Nascente 4 (Figura 3) está localizada na região de Lucaia e apresenta uma cobertura vegetal bem preservada, sendo circundada por $100 \%$ de floresta ombrófila em estágio inicial no raio de $50 \mathrm{~m}$ (Tabela 2), estando em conformidade com a legislação (Brasil 2012). Essa APP é cercada e o gado não tem acesso a essa nascente. A mata dessa nascente apresenta vegetação pouco alterada e de alto porte (Figura 4) e foi classificada como preservada, conforme metodologia de Pinto et al. (2004). Observou-se que após o fragmento de mata a nascente é circundada por pastagem, sendo a bovinocultura de corte um cultivo forte na região.

A Nascente 5 (Figura 3) possui as mesmas características da Nascente 4, localizada na mesma região de Lucaia, com cobertura vegetal bem preservada, circundada por $100 \%$ de floresta ombrófila em estágio inicial (Tabela 2) no raio de 50 metros, estando em conformidade com a legislação vigente (Brasil 2012). Essa APP também é cercada e o gado não tem acesso a essa nascente. A mata dessa nascente apresenta vegetação pouco alterada e de alto porte (Figura 4) e foi classificada como preservada, conforme metodologia de Pinto et al. (2004).

A Nascente 6 (Figura 3) está localizada na região de Lucaia e pertence à mesma fazenda da Nascente 4 e

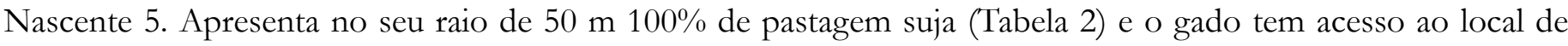
afloramento da nascente. Existe também uma barreira de concreto construída com o intuído de represar a água minada (Figura 4). Essa nascente foi classificada como degradada, conforme metodologia de Pinto et al. (2004) e não está em conformidade com a legislação (Brasil 2012).

A Nascente 7 (Figura 3) está localizada também na região de Lucaia e um pouco mais à frente da Nascente 6, estando já em outra propriedade. A Nascente 7 apresenta sinais de perturbação com indícios de desmatamento recente, na data da visita (18/10/16), com solo revolvido por maquinário de grande porte (Figura 4). Possui 100\% da área destinada à APP coberta por pastagem suja (Tabela 2) e ainda possui nas suas proximidades lavoura de café. Essa nascente não está em conformidade com a legislação vigente (Brasil 2012), pois não possui o raio mínimo de 50 metros recomendados por lei e segundo metodologia de Pinto et al. (2004) está classificada como degradada.

A Nascente 8 (Figura 3) está localizada bem próxima à cidade de Planalto-BA e não apresenta nenhuma área de vegetação florestal no seu entorno, sendo ocupada no raio de $50 \mathrm{~m}$ por $100 \%$ de pastagem limpa utilizada na criação do gado de corte (Tabela 2). Segundo metodologia de Pinto et al. (2004) esta nascente foi classificada como degradada, não estando em conformidade com a legislação vigente (Brasil 2012). Além disso, foi verificada a presença de taboa (Thypha domingensis Pers.) logo após seu afloramento (Figura 4), o que possivelmente contribui para diminuição da velocidade da água, além do aumento de matéria orgânica, o que pode intensificar o desenvolvimento de microorganismos. Foi observada também uma faixa de contorno não vegetada utilizada como estrada, o que torna a área ainda mais desprotegida.

De acordo com os critérios estabelecidos, dentre as oito nascentes visitadas, apenas duas encontram-se preservadas, e isto representa $25 \%$ das nascentes, e as outras seis nascentes (75\%) apresentaram-se degradadas. As nascentes classificadas como preservadas estão em conformidade com a legislação vigente (Brasil 2012) e as nascentes classificadas como degradadas não estão em conformidade com a legislação por não apresentarem vegetação nativa no raio de $50 \mathrm{~m}$. Estes resultados demonstram que o estado de conservação das nascentes do rio Gaviãozinho (Tabela 1) é preocupante, apontando para uma necessidade de conscientização do uso do solo no entorno das nascentes e também dos leitos dos rios, com o intuito de preservar a qualidade das águas.

Os impactos mais significantes são decorrentes da aproximação e intervenção antrópica nas nascentes e também ausência da mata ciliar, acarretando em alterações nos parâmetros do índice de qualidade da água (Garcia et al. 2018). Na maior parte dos casos os fatores de perturbação estão relacionados à atividade agropecuária ao redor das nascentes, sendo assim, há necessidade de efetivo acompanhamento de práticas de manejo e conservação dos solos utilizados nas propriedades visto que essas atividades são de extrema importância econômica para região. Vaz e Orlando (2012) estudando a importância das matas ciliares para manutenção da qualidade das águas de nascentes também verificaram um intenso uso do solo aproximadamente de $80 \%$, sendo que a pastagem foi a cobertura vegetal predominante. 
As áreas habitadas, agricultura e matas degradadas podem reduzir, de maneira geral, a vazão específica e a qualidade de água de uma Bacia hidrográfica (Vanzela et al. 2010). Assim, não somente os cinquenta metros que circunda as nascentes merecem atenção quanto à preservação da vegetação e do solo, mas toda a área da bacia que contribui para a recarga de água, pois esse ambiente preservado auxilia no controle à erosão e melhoria das características físicas do solo, assegurando uma melhor retenção e infiltração da água da chuva.

Na bacia do rio Catolé o uso do solo é diversificado, sendo que, em geral, nos fundos de vales planos e argilosos a olericultura tem papel importante. A criação de gado também se destaca na região enquanto que em direção à escarpa do planalto de Vitória da Conquista, principalmente na faixa que vai da cidade de Barra do Choça até a borda da escarpa, a cultura do café assume relevância, principalmente na área de relevo plano e suave ondulado sobre solos profundos (Bonfim et al. 2012).

As pastagens recobrem 74,3\% das terras dos municípios que compõem a bacia do rio Catolé Grande sendo estas constituídas de capim braquiária (Brachiaria decumbens Stapf) e capim colonião (Panicum maximum), pastagens naturais (formadas a partir da derrubada das matas), plantio de culturas anuais e o posterior rebroto de espécies herbáceo/arbustivas e áreas plantadas com forrageiras para corte, sendo que no município de Planalto 70,5\% da área rural é ocupada por pastagem (Lima e Pinto 2011).

\section{Qualidade da água das nascentes}

$\mathrm{Na}$ Tabela 3 estão apresentadas as diferentes variáveis de qualidade de água das nascentes avaliadas do rio Gaviãozinho da cidade de Planalto-Ba.

Tabela 3: Valores médios e respectivos desvios padrões de $\mathrm{pH}$, Condutividade Elétrica, Turbidez, Oxigênio Dissolvido e Demanda Bioquímicas de Oxigênio (DBO) das nascentes avaliadas do rio Gaviãozinho da cidade de Planalto - BA

\begin{tabular}{|c|c|c|c|c|c|}
\hline Nascentes & $\mathbf{p H}$ & $\mathbf{C E}\left(\boldsymbol{\mu} \mathbf{S ~ c m}^{-1}\right)$ & TUR(UNT) & $\mathbf{O D}\left(\mathbf{m g ~ L}^{-1}\right)$ & $\mathbf{D B O}\left(\mathbf{m g ~ L}^{-1}\right)$ \\
\hline N1 & $5,65 \pm 0,11 \mathrm{~b}$ & $30,08 \pm 1,17 \mathrm{f}$ & $8,49 \pm 0,59 \mathrm{~b}$ & $6,75 \pm 0,23 \mathrm{ab}$ & $4,49 \pm 0,89 \mathrm{~ns}$ \\
N2 & $6,10 \pm 0,11 \mathrm{a}$ & $106,55 \pm 3,36 \mathrm{c}$ & $104,00 \pm 6,08 \mathrm{a}$ & $4,95 \pm 0,48 \mathrm{c}$ & $2,99 \pm 1,67 \mathrm{~ns}$ \\
N3 & $6,05 \pm 0,10 \mathrm{ab}$ & $127,31 \pm 4,16 \mathrm{~b}$ & $77,26 \pm 26,26 \mathrm{a}$ & $6,60 \pm 0,18 \mathrm{ab}$ & $5,82 \pm 3,33 \mathrm{~ns}$ \\
N4 & $6,37 \pm 0,03 \mathrm{a}$ & $50,12 \pm 4,57 \mathrm{e}$ & $5,37 \pm 1,07 \mathrm{~b}$ & $6,38 \pm 0,32 \mathrm{ab}$ & $6,64 \pm 1,85 \mathrm{~ns}$ \\
N5 & $6,11 \pm 0,13 \mathrm{a}$ & $47,23 \pm 0,95 \mathrm{e}$ & $17,23 \pm 0,25 \mathrm{~b}$ & $6,60 \pm 0,91 \mathrm{ab}$ & $7,72 \pm 5,06 \mathrm{~ns}$ \\
N6 & $6,20 \pm 0,04 \mathrm{a}$ & $106,16 \pm 2,55 \mathrm{c}$ & $19,14 \pm 0,05 \mathrm{~b}$ & $6,08 \pm 0,14 \mathrm{~b}$ & $7,61 \pm 3,7 \mathrm{~ns}$ \\
N7 & $6,29 \pm 0,28 \mathrm{a}$ & $65,44 \pm 3,32 \mathrm{~d}$ & $13,27 \pm 0,09 \mathrm{~b}$ & $6,87 \pm 0,92 \mathrm{a}$ & $6,11 \pm 0,72 \mathrm{~ns}$ \\
N8 & $6,30 \pm 0,17 \mathrm{a}$ & $1139,23 \pm 6,60 \mathrm{a}$ & $13,46 \pm 0,27 \mathrm{~b}$ & $4,64 \pm 0,35 \mathrm{c}$ & $9,39 \pm 2,62 \mathrm{~ns}$ \\
\hline
\end{tabular}

pH= Potencial Hidrogeniônico; $\mathrm{CE}=$ Condutividade Elétrica; $\mathrm{TUR}=$ Turbidez; $\mathrm{DBO}=$ Demanda Bioquímica de Oxigênio; Médias seguidas pelas mesmas letras nas linhas não diferenciam significativamente entre si pelo teste de Tukey a $5 \%$ de probabilidade

$\mathrm{O}$ pH das águas das nascentes avaliadas, de N2 a N8 não apresentaram diferenças significativas a 5\% de probabilidade pelo teste de Tukey (Tabela 3), sendo os valores deste parâmetros compatíveis com os estabelecidos

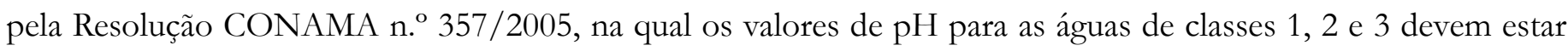
na faixa de 6,0 a 9,0 (Brasil 2005). Em contrapartida, o pH da nascente $\mathrm{N} 1$ não apresentou diferença significativa pelo teste de tukey a $5 \%$ de probabilidade em relação a N3, porém diferiu significativamente das demais nascentes, estando este parâmetro abaixo dos estabelecidos para esta variável segundo a mesma resolução.

Segundo Matheus et al. (1995), no ambiente natural, a água tem sua concentração de íons $\mathrm{H}^{+}$e $\mathrm{OH}^{-}$altamente influenciada por sais, ácidos e bases presentes no meio, o que pode fornecer informações sobre sua qualidade, tipo de solo por onde passou, tipo de poluição da água e a qualidade do ambiente. 
No presente estudo não foi constatada correlação entre o grau de preservação da nascente e os valores de $\mathrm{pH}$. Marmontel e Rodrigues (2015) verificaram que ambientes com mata ciliar, independente do grau de preservação, influenciou no equilíbrio dos valores de $\mathrm{pH}$. Lima (2010) encontrou maiores valores de pH nos ambientes com presença de mata ciliar preservadas.

Os valores médios de condutividade variaram entre 30,08 a $1139,23 \mu \mathrm{S} \mathrm{cm}^{-1}$. O menor valor de $\mathrm{CE}$ foi constatado na nascente $\mathrm{N} 1\left(30,08 \mu \mathrm{S} \mathrm{cm}^{-1}\right)$, embora a mesma tenha grau de preservação degradada, seguida das nascentes $\mathrm{N} 4\left(50,12 \mu \mathrm{S} \mathrm{cm} \mathrm{cm}^{-1}\right)$ e N5 $\left(47,23 \mu \mathrm{S} \mathrm{cm}^{-1}\right)$ que não apresentaram diferenças estatísticas entre si pelo teste de Tukey a $5 \%$ de probabilidade (Tabela 3). A maioria das nascentes degradadas apresentou valores maiores de condutividade em relação às nascentes preservadas.

Os elevados valores da CE em N8 são reflexos de grandes quantidades de íons em solução na água. A utilização de fertilizantes nas pastagens bem como os resíduos oriundos da pecuária pode estar contribuindo para o aumento da CE nesta nascente. Além disso, a nascente está localizada a pouco mais de 300 metros do perímetro urbano.

A nascente N7 apesar de degradada obteve valores de CE inferiores quando comparada às outras nascentes com o mesmo grau de preservação, fato este corroborado por Marmontel e Rodrigues (2015), que associaram valores considerados baixos de condutividade elétrica em uma nascente à manutenção de mata ciliar, ainda que no estado de conservação perturbada, enquanto Arcova e Cicco (1999) não constataram influência do uso do solo em relação à CE.

As nascentes N2 e N3, caracterizadas como degradadas, apresentaram diferenças significativas em relação às outras nascentes para a característica física turbidez a 5\% de probabilidade pelo teste de Tukey (Tabela 3).

As nascentes N2 e N3 apresentaram os mais altos valores de turbidez, 104,0 e 77,26 UNT, respectivamente, não apresentando diferenças significativas entre si a 5\% de probabilidade pelo teste de Tukey (Tabela 3). Os valores de turbidez das outras nascentes (N1, N4, N5, N6, N7 e N8) não apresentaram diferenças significativas entre si a 5\% de probabilidade pelo teste de Tukey, sendo menores e diferentes apenas das nascentes N2 e N3.

Valores elevados de turbidez podem ter ocorrido em razão do carreamento de partículas de solos erodidos na área da nascente ocasionada pelo manejo inadequado do solo naquele local. O solo erodido carreado para a nascente fez alterar a coloração e a turbidez da água o que corrobora com os achados de Arcova, Cicco e Honda (2003).

$\mathrm{Na}$ nascente $\mathrm{N} 2$ a presença de estrada nas proximidades e o acesso contínuo pelo gado para dessedentação pode ter provocado a alteração da turbidez, fato constatado no estudo de Guerra, Silva e Botelho (1999). A norma legal permite o acesso de pessoas e animais nas APP's para obtenção de água e para realização de atividades de pequeno impacto ambiental. Normalmente o gado é o animal mais encontrado nessas áreas, sendo que esse possui a capacidade de prejudicar a qualidade da água, bem como, comprometer o estado de preservação da mesma, que através do pisoteio degrada e promove destruição gradativa das nascentes, caso estas não estejam cercadas adequadamente (Vaz e Orlando 2012).

Primavesi et al. (2002) e Donadio et al. (2005) verificaram mais altos valores de turbidez em microbacias agrícolas em relação às áreas florestadas, destacando assim, a função da mata ciliar na contenção de partícula que poderiam vir a alcançar a água.

As nascentes N2 e N8 (degradadas) apresentaram a menor concentração de OD e diferença significativa a $5 \%$ de probabilidade pelo teste Tukey em comparação às nascentes com mesmo estado de conservação (Tabela 3). Essas nascentes foram classificadas como degradadas, assim o nível de OD pode apresentar-se menor devido a processos eutróficos decorrentes de atividades humanas (Valente et al.1997). Esses valores alterados podem ser atribuídos aos dejetos provenientes da atividade pecuária intensiva que chegam ao curso d'água, aliado também a uma provável contaminação por efluentes domésticos, no caso da nascente $\mathrm{N} 8$, que se encontra a pouco mais de 300 metros do perímetro urbano.

Os baixos valores de oxigênio dissolvidos encontrados indicam a presença de matéria orgânica na água das nascentes N2 e N8, que acaba por consumir o OD para degradação dos compostos orgânicos. Pinto et al. (2012) 
avaliando a qualidade da água de nascentes com diferentes usos do solo em seu entorno, verificaram que na nascente margeada com café, o emprego de defensivos agrícolas na lavoura afetaram os valores de OD e de fosfato total na água.

Nas nascentes N4 e N5, classificadas como preservadas, os valores de oxigênio foram altos, 6,38 e 6,60 mg $\mathrm{L}^{-1}$, respectivamente, não diferindo significativamente dos valores de oxigênio dissolvido das nascentes N1 e N7, classificadas como degradadas (Tabela 3). Segundo a Resolução CONAMA n. 357 (Brasil 2005), os valores de oxigênio dissolvido para as águas doce classe 2 tem de ser, no mínimo, $5 \mathrm{mg} \mathrm{L}^{-1}$, critério este que as nascentes degradadas, N2 e N8 não atendem, pois apresentaram valores de OD inferiores, sendo estes de 4,95 e 4,64 mg L $\mathrm{L}^{-1}$, respectivamente. Segundo Sperling (2005), o oxigênio dissolvido é um parâmetro essencial para a caracterização dos efeitos de poluição por dejetos orgânicos.

Back et al. (2008) avaliando a qualidade da água na microbacia Maracanã, Sombrio-SC, encontrou em 9,1\% das amostras das águas das nascentes valores de OD abaixo do limite inferior estabelecido pela resolução CONAMA n. 357 (Brasil 2005), enquanto que todas as amostras da foz apresentaram valores de OD acima do limite inferior e destaca que existe uma relação inversa do teor de OD com a altitude e temperatura, onde em temperaturas mais elevadas ou em altitudes maiores a concentração de OD dissolvido na água é menor.

Não houve diferença significativa entre os valores de DBO mensurados, o que corrobora com resultados encontrados por Donádio et al. (2005), que analisando a qualidade da água de nascentes com diferentes usos do solo na bacia hidrográfica do córrego rico em São Paulo, verificou que a DBO não obteve grande importância relativa, por apresentar valor de $\mathrm{F}$ pequeno e por ser um parâmetro com pouca variação dos valores médios. A Resolução CONAMA no 357 (Brasil 2005), estabelece $\mathrm{DBO}_{5,20}$ até $5 \mathrm{mg} \mathrm{L}^{-1}$ para rios de Classe 2. Este parâmetro representa a quantidade de oxigênio necessária para oxidar a matéria orgânica presente na água através da decomposição microbiana aeróbia (Ana 2018).

A presença de vegetação ciliar remanescente contribui na proteção dos recursos hídricos (Donádio et al. 2005). Primavesi et al. (2002) e Donadio et al. (2005), analisando a qualidade da água em áreas usos do solo diferentes, concluíram que, na nascente provida de mata ciliar, a qualidade da água foi melhor que nas nascentes com uso agrícola, sendo que as variáveis que mais explicaram essas diferenças foram: cor, dureza, turbidez, condutividade elétrica, alcalinidade, $\mathrm{pH}$, demanda química de oxigênio (DQO) e oxigênio dissolvido (OD). Esses dados corroboram com os resultados dessa pesquisa, onde as nascentes preservadas apresentaram maior estabilidade dos parâmetros avaliados, podendo inferir que as APP's contribuem para melhor qualidade da água.

Bueno et al. (2005) realizou o monitoramento de variáveis de qualidade da água e verificou que a cobertura vegetal contribuiu para a estabilidade da temperatura da água, fato este que influenciou outras variáveis (OD, MO e $\mathrm{pH}$ ), sugerindo que o manejo no uso do solo é extremamente importante para a qualidade da água.

Agrizze et al. (2018) estudando a qualidade da água de nascentes concluíram que o a proteção das nascentes com cerca contribuiu com a melhoria da qualidade da água e que a nascente sob pastagem sem proteção de cerca apresentou qualidade da água inferior em relação à nascente com cerca.

Dentre os vários benefícios da presença da mata ciliar, a contribuição desta para a manutenção da qualidade da água é de extrema importância, pois mesmas possui função tampão, filtrando e retendo parte significativa da água advinda das áreas adjacentes que escoam para dentro dos cursos d'água. Assim, ficam retidos grande quantidade de sólidos, produtos tóxicos e nutrientes, tais como fósforo e nitrogênio, que em excesso na água podem provocar o aumento exagerado de algas e plantas aquáticas (Lima e Zakia 2001). 


\section{CoNCLUSÕES}

Tendo por base os resultados obtidos, pode-se concluir que:

- O rio Gaviãozinho em Planalto-BA possui 08 nascentes principais;

- Apenas $25 \%$ das nascentes avaliadas apresentaram-se preservadas e em conformidade com a legislação (Brasil 2012) com o raio de APP maior que 50 metros e sem perturbação evidente;

- 75\% das nascentes avaliadas foram classificadas como degradadas e não apresentaram conformidade com a legislação (Brasil 2012) exibindo algum grau de perturbação e vegetação escassa;

- O pH não apresentou correlação com o grau de preservação das nascentes.

- A condutividade elétrica das águas das nascentes variou entre 30,08 e 1139,23 $\mu \mathrm{S} \mathrm{cm}^{-1}$, sendo os maiores valores encontrados em nascentes degradadas, que não estavam em conformidade com a legislação (Brasil 2012);

- A turbidez das águas das nascentes variou entre 5,37 a 104,0 UNT, sendo os maiores valores encontrados em nascentes degradadas, que não estavam em conformidade com a legislação (Brasil 2012);

- O OD das águas das nascentes variou entre 4,64 e 6,75, e os menores valores encontrados foram em nascentes degradadas, abaixo do limite estabelecido pela Resolução CONAMA 357 de 2005 para águas de classe II;

- A DBO não apresentou diferença significativa entre os valores mensurados;

- Nas nascentes com presença de mata ciliar, em conformidade com a legislação (Brasil 2012), foram observadas menores variações nos parâmetros avaliados quando comparadas à maioria das nascentes que não possuíam cobertura do solo com vegetação natural;

- As áreas das nascentes diagnosticadas, embora protegidas por lei, vêm sofrendo um processo de degradação acentuado, havendo a necessidade de ações de recuperação.

\section{REFERÊNCIAS}

ANA-Agência Nacional de Águas. Indicadores de Qualidade da água. Disponível em: http://portalpnqa.ana.gov.br/ indicadores-indice-aguas.aspx . Acesso em: 04 dez. 2018.

Agrizzi DV, Cecílio RA, Zanetti SS, Garcia GO, Amaral AA, Firmino EFA, Mendes NGS. 2018. Qualidade da água de nascentes do Assentamento Paraíso. Engenharia Sanitária e Ambiental, 23 (3): 557-568

ASSOCIAÇÃO BRASILEIRA DE NORMAS TÉCNICAS. 1987. NBR 9897: planejamento de amostragem de efluentes líquidos e corpos receptores - procedimento. Rio de Janeiro.

ASSOCIAÇÃO BRASILEIRA DE NORMAS TÉCNICAS. 1992. NBR 12614: Águas - Determinação da demanda bioquímica de oxigênio (DBO) - Método de incubação $\left(20^{\circ} \mathrm{C}\right.$, cinco dias). Rio de Janeiro.

Arcova FCS, Cicco V. 1999. Qualidade da água de microbacia com diferentes usos do solo na região de Cunha, Estado de São Paulo. Scientia Forestalis, 56: 125-134.

Arcova FCS, Cicco V, Honda, EA. 2003. Sul. In: Workshop em Manejo de Bacias Hidrográficas, 7, Anais..., Botucatu.

Back AJ, Zampieri SL, Baldissera IT, Deschamps F, Vieira HJ. 2008. Monitoramento da qualidade da água em microbacias: estudo de caso da microbacia Maracanã, Sombrio - SC. In: VIII Encontro Nacional de Engenharia de Sedimentos, Anais..., Campo Grande. 
Barros FM, Rocha FA, Fraga MS, Generoso TN, Melo ARB. 2011. Variação da turbidez em pontos distintos de um perfil transversal do Rio Catolé-Ba sob diferentes níveis de vazão. Enciclopédia Biosfera, 7 (12):1-6.

Bomfim DA, Santos JO, Sampaio RJ, Silva Junio MF. 2012. Considerações sobre as mudanças climáticas e os impactos na sub-bacia do rio Catolé para o município de Vitória da Conquista-Bahia. Revista Eletrônica do Mestrado em Educação Ambiental, 29:1517:1256.

BRASIL (Governo do). Lei $\mathbf{n}^{\circ}$ 12.651, de 25 de maio de 2012. Dispõe sobre a proteção da vegetação nativa. Brasília: Ministério do meio ambiente.

BRASIL (Governo do), CONAMA. Resolução N 357, DE 17 DE MARÇO DE 2005. Dispõe sobre a classificação dos corpos de água e diretrizes ambientais para o seu enquadramento, bem como estabelece as condições e padrões de lançamento de efluentes, e dá outras providências. 27 p.

Bueno LF, Galbiatti JA, Borges MJ. 2005. Monitoramento de variáveis de qualidade da água do horto ouro verde - Conchal - SP. Engenharia Agrícola, 25(3):742-748.

Donadio NMM, Galbiatti JA; de Paula RC. 2005. Qualidade da água de nascentes com diferentes usos do solo na bacia hidrográfica do córrego rico, São Paulo, Brasil. Engenharia Agrícola, 25(1): 115-125.

Garcia JM, Mantovani P, Gomes RC, Longo RM, Demanboro AC, Bettine SC. 2018. Degradação ambiental e qualidade da água em nascentes de rios urbanos. Sociedade \& Natureza, 30(1): 228-254.

Guerra AJT, Silva AS, Botelho RGM.1999. Erosão e conservação de solos: conceitos temas e aplicações. Rio de Janeiro: Bertrand Brasil, 339 p.

Huller A. 2011. Restauração florestal através de semeadura direta de duas espécies nativas. Dissertação (Mestrado em Ciência e tecnologia de Sementes) - Universidade Federal de Pelotas, RS. Pelotas, 89p

Lima EM, Pinto, JE. 2011. Bacia do rio Catolé, Bahia - Brasil: bases geoambientais e socioeconômicas para a gestão da água e do solo. Revista Geográfica de América Central, Número Especial:1-11.

Lima WP, Zakia, MJB. 2001. Hidrologia de Matas Ciliares. In: Matas Ciliares: conservação e recuperação, 2 ed., São Paulo: Ed. da Universidade de São Paulo p. 33-44.

Marmontel, CVF, Rodrigues VA. 2015. Parâmetros indicativos para qualidade da água em nascentes com diferentes coberturas de terra e conservação da vegetação ciliar. Floresta e Ambiente, 22(2): 171-181.

Martins SV. 2001. Recuperação de Matas Ciliares. Viçosa: Aprenda Fácil, 246 p.

Matheus CE, Moraes AJ, Tundisi TM, Tundisi, JG. 1995. Manual de análises limnológicas. São Carlos: Centro de Recursos Hídricos e Ecologia Aplicada, USP, 62 p.

Pinto LVA, Botelho SA, Davide AC, Ferreira, E. 2004. Estudo das nascentes da bacia hidrográfica do Ribeirão Santa Cruz, Lavras, MG. Scientia Florestalis, 65:197-206.

Pinto LVA, Roma T N de, Balieiro KRC. 2012. Avaliação qualitativa da água de nascentes com diferentes usos do solo em seu entorno. Cerne, 18 (3): 495-505. 
Primavesi, O, Freitas, AR, Primavesi AC, Oliveira HT. 2002. Water quality of Canchim's creek watershed in São Paulo, SP, Brazil, occupied by beef and dairy cattle activities. Brazilian Archives of Biology and Technology, 45 (2): 209-17.

SEI-Superintendência de Estudos Econômicos e Sociais da Bahia. Disponível em http://sim.sei.ba.gov.br/sim/tabelas. wsp\#. Acesso em jun 2017.

Silva Junior LG. 2015. Ação antrópica em torno das nascentes da Microbacia do Rio Bitury, Município de Belo Jardim (Região Agreste de Pernambuco). Revista Brasileira de Gestão Ambiental e Sustentabilidade, 2(3): 105-119.

Valente JPS, Padilha PM, Silva AMM. 1997. Contribuição da cidade de Botucatu, SP com nutrientes (fósforo e nitrogênio) na eutrofização da represa de Barra Bonita. Eclética Química, 22: 31-48.

Vaz L, Orlando PHK. 2012. Importância das matas ciliares para manutenção da qualidade das águas de nascentes: diagnóstico do ribeirãoVai-Vem de Ipameri - GO. In: Encontro Nacional de Geografia Agrária, XXI, Uberlândia. Anais... ,Uberlândia.

Vanzela LS, Hernandez FBT, Franco RAM. 2010. Influência do uso e ocupação do solo nos recursos hídricos do Córrego Três Barras, Marinópolis. Revista Brasileira de Engenharia Agrícola e Ambiental, 14(1): 55-64.

Von Sperling M. 2005. Introdução a qualidade das águas e ao tratamento de esgotos, 3 ed., Belo Horizonte: Departamento de Engenharia Sanitária e Ambiental, 452 p. 